\title{
Maternal and child under-nutrition in rural and urban communities of Lagos state, Nigeria: the relationship and risk factors
}

\author{
Idowu O Senbanjo ${ }^{1,4^{*}}$, Ibiyemi O Olayiwola ${ }^{2}$, Wasiu A Afolabi ${ }^{2}$ and Olayinka C Senbanjo ${ }^{3}$
}

\begin{abstract}
Background: Poor nutritional status of mothers has a direct and indirect consequence on their own health and that of their children. The objective of this study was to determine the relationship between nutritional status of mothers and their children and the risk factors for under-nutrition among mothers and children in rural and urban communities of Lagos State, Nigeria.
\end{abstract}

Methods: This was a cross sectional survey conducted using the multistage random sampling technique. A total of 300 mother-child pairs were studied, consisting of 150 each from rural and urban communities. Under-nutrition in mothers and children was determined using standard criteria.

Results: The prevalence of under-nutrition among mothers was significantly higher in rural than urban communities ( $10.7 \%$ vs. $2.7 \%, p=0.014)$. The prevalences of underweight and stunted children were also significantly higher in rural than urban communities (19.4\% vs. 9.3\%, $p<0.001)$ and $(43.3 \%$ vs. $12.6 \%, p<0.001)$ respectively. In rural communities, the risk of stunted mothers having children with stunting was about 7 times higher than those who were not (OR 6.7,95\% Cl=1.4-32.0, $\mathrm{p}=0.007)$. In urban communities, undernourished mothers have about 11 and 12 times risk of having children with underweight and wasting respectively (OR 11.2, $95 \% \mathrm{Cl}=1.4-86.5, \mathrm{p}=0.005)$ and (OR $12.3,95 \% \mathrm{Cl}=1.6-95.7, \mathrm{p}=0.003$ ) respectively. The identified risk factors for maternal and child under nutrition differs across rural and urban communities.

Conclusions: The prevalence of maternal and child under-nutrition is high in both communities although higher in rural communities. Efforts at reducing the vicious cycle of under-nutrition among mothers and children should concentrate on addressing risk factors specific for each community.

Keywords: Mother, Children, Under-nutrition, Risk factors, Rural, Urban, Nigeria

\section{Background}

The nutritional status of a mother is important, both as an indicator of her overall health and as a predictor of pregnancy outcome for both mother and child [1,2]. Adequate maternal nutrition is needed for breastfeeding, recovery following the stress of pregnancy and labour, coping with child rearing and care and also preparation for future pregnancies [1]. A mother who was malnourished

\footnotetext{
* Correspondence: senbanjo001@yahoo.com

${ }^{1}$ Department of Paediatrics and Child Health, Lagos State University College of Medicine, Ikeja, Lagos PMB 21266, Nigeria

${ }^{4}$ Department of Paediatrics and Child Health, Paediatrics Gastroenterology/ Hepatology/Nutrition Unit, Lagos State University Teaching Hospital, Ikeja, Lagos, Nigeria

Full list of author information is available at the end of the article
}

as a fetus, young child or adolescent is more likely to enter pregnancy stunted and malnourished. Her compromised nutritional status affects the health and nutrition of her own children. These intergenerational effects can be turned into a vicious cycle perpetuating malnutrition from one generation to the next [3].

The consequences of poor maternal nutritional status are reflected in high infant and maternal morbidity and mortality $[4,5]$. Globally, more than 3.5 million mothers and children under five years of age die unnecessarily each year due to the underlying cause of under-nutrition, and millions more are permanently disabled by the physical and mental effects of poor nutrition, the vast majority in south-central Asia and sub-Saharan Africa [5]. 
The United Nations provided eight Millennium Development Goals (MDG), which serve as a framework for the entire international community to work together to reduce child morbidity and mortality [6]. These goals were adopted by all world leaders in 2000 and are set to be achieved by 2015. In Nigeria, an evaluation of the MDG between 2000 and 2007 showed that their achievement in reducing child mortality rate was unsatisfactory, while the maternal mortality rate was actually increasing [7]. Mid-way to the end of the MDG's implementation period, there remain wide gaps between targets and actual achievement particularly in the rural communities. It is a well-known fact that, attainment of many of these MDG's requires good nutrition status for children and adolescent girls.

Nigeria is the most populous country in Africa, with a population of about 148 million. About sixty percent of this population resides in the rural areas, while about forty-four percent of the population is made up of children and mothers [8]. In Lagos state, Nigeria, the infant mortality rate is 85 deaths per 1000 live births, relatively better than the national average. The maternal mortality rate is 650 deaths per 100,000 live births [9]. Most of these deaths have malnutrition as the predisposing factor, either directly or indirectly. However, these deaths are preventable. The risk factors for under-nutrition among mothers and children have been well described but data establishing differences in risk factors for under-nutrition between urban and rural communities for both mothers and children are few.

Therefore, this study was carried out to determine the relationship between the nutritional status of mothers and their children and the risk factors for under-nutrition among mothers and children living in rural and urban communities of Lagos state, Nigeria.

\section{Methods \\ Study area}

The study was carried out in the Epe Local Government Area and the Alimosho Local Government Area in Lagos State, Nigeria, which were randomly selected from the 20 local governments in Lagos state officially recognized by the Federal government of Nigeria.

Lagos state is Nigeria's former capital city. The vegetation is that of the tropical rain forest. It has an annual rainfall of 180 centimeters and a mean temperature of $26^{\circ} \mathrm{C}$. It is $200-500$ meters above sea level. Lagos has a very diverse and fast-growing population, resulting from heavy and ongoing migration to the city from all parts of Nigeria as well as neighbouring countries. Though the Yoruba, an African people inhabiting southwest Nigeria, constitute the city's principal ethnic group, there are a significant proportion of other ethnic groups, particularly the Ibos, Ibibio and Hausa.

\section{Study design}

The study was a cross sectional survey of women in the reproductive age group and their children aged zero to fifty-nine months, in rural and urban communities located in randomly selected Local Government Areas of Lagos State, Nigeria.

\section{Ethical clearance}

Ethical clearance was obtained from the Lagos State University Teaching Hospital Research/Ethics Committee; permission was also obtained from the parents that were involved.

\section{Method of sampling}

A multistage random sampling technique was used to select subjects. Epe and Agbowa were randomly selected from the Epe LGA, representing urban and rural communities, respectively, while Akowonjo and Orisumbare were selected from the Alimosho LGA, representing urban and rural communities, respectively. From each communities, houses were selected ramdomly using the table of random numbers.

The sample size: The minimum number of the subjects ' $n$ ' required for the study was estimated from the formula:

$$
\mathrm{n}=\mathrm{z}^{2} \mathrm{p}(1-\mathrm{p}) \div \mathrm{d}^{2}
$$

Where: ' $\mathrm{z}$ ' is the critical value and in a two-tailed test it is equal to 1.96 .

' $\mathrm{p}$ ' is the estimated prevalence of malnutrition in women, which was taken as 9 percent, based on an earlier report by Nigerian Food Consumption and Nutrition Survey for Southwestern part of Nigeria [10].

' $\mathrm{d}$ ' is the absolute sampling error that can be tolerated. In this study, it was fixed at 5 percent.

Therefore the minimum sample size: ' $n$ ' $=1.96^{2} \times$ $0.09 \times(1-0.09) \div 0.05^{2}=125.9$ which is approximately 126. Taking into consideration a possible attrition rate of 10 percent, the minimum sample size for this study will be 137 .

This was rounded up to 150 each for rural and urban communities.

In each household, the parents of children aged zero to fifty-nine months were identified, and informed consent was obtained prior to the beginning of the study. The parents were interviewed according to the proforma specifically designed for the study. Information was obtained on demographic, socio-economic and environmental characteristics of the family. The families were assigned a socioeconomic class using the method recommended by Ogunlesi et al [11]. The parents' occupations and highest education attained were scored from 1 (highest) to 5 (lowest). The mean score for both parents gave the social class, falling within the $1-5$ range. Those with mean scores of 1 and 2 
were further classified as upper class, those with mean score of 3 were classified as middle class, while those with mean scores of 4 and 5 were classified as falling in the lower social class.

\section{Anthropometry}

The children were weighed using an electronic weighing scale calibrated in $100 \mathrm{~g}$ units (SECA/UNICEF, Australia). Children who were too scared to stand on the scale were weighed together with the mother, and the mother's weight automatically deducted to obtain the weight of the child. All children were weighed naked and to the nearest $0.1 \mathrm{~kg}$.

Length of children aged less than twenty-four months was measured using an infantiometer. This was done on a firm surface with assistance, usually by the mother. The knees were held down and the head held firmly against the headboard. These measurements were done to the nearest $0.1 \mathrm{~cm}$. Height was measured using a height board for children aged twenty-four to fifty-nine months. This was done with the children standing erect without shoes, with eyes facing forward and the feet together on the horizontal plane.

The mother's weight was measured using the same weighing scale used for children.

The height of the mothers was also measured using a height board. This was done with the mothers standing erect, without shoes, with eyes facing forward and feet together on the horizontal plane. Standardization checks on the tools for anthropometric measurements were done periodically.

Malnutrition in children was calculated from the degree of stunting (height-for-age), underweight (weight-for-age) and wasting (weight-for-height) following World Health Organization (WHO) guidelines and cut off points [12]. In this study, a child was said to be underweight, wasted and stunted if the Weight-for-Age, Weight-for-Height and Height-for-Age were below minus two Standard Deviation (-2 SD) from the median of each international reference standard, respectively.

A mother was said to be undernourished if her BMI was less than $18.5 \mathrm{Kg} / \mathrm{m}^{2}$, or stunted if her height was less than $152 \mathrm{~cm}$ [12].

\section{Statistical analysis}

WHO Anthro 2007 was used to generate z-score values for weight-for-age, height-for-age and weight-for-height. All data were entered into and analysed using SPSS for windows software version 13. The means and standard deviations (SD) were calculated for continuous variables, while ratios and proportions were calculated for categorical variables. Categorical variables were compared using the Pearson Chi square $(\chi 2)$ test. Independent $t$-test was used to calculate mean differences for continuous variables between urban and rural communities. Using logistic regression, odds ratio and its $95 \%$ confidence interval were used to calculate risk of occurence of under-nutrition in a child if the mother is undernourished. 'P' values less than 0.05 were accepted as statistically significant.

\section{Results}

\section{Socio-demographic characteristics}

A total of 300 mother-child pairs were studied, consisting of 150 each from rural and urban communities, and the results obtained were analysed. Table 1 shows the sociodemographic characteristics and nutritional status of the study population according to their place of residence.

Age at first birth of mothers in rural communities was significantly lower than for mothers in urban communities $(\mathrm{p}<0.001)$. Polygamous homes was siginificantly common in rural than uban communities $(\mathrm{p}<0.001)$ while the parity of mothers was higher in rural than urban communities $(\mathrm{p}<0.001)$. The educational level of mothers was significantly better in urban as opposed to rural areas $(\mathrm{p}<0.001)$ and a significant proportion of the mothers in rural compared with urban communities $(90.0 \%$ vs. $60.4 \%, \mathrm{p}<0.001$ ) were from the lower social class.

The mean age of the children in the rural communities was significantly higher than that of children from urban communities (31.3 vs. 19.3 months; $\mathrm{p}<0.001$ ). Gender distributions of the children were not statistically different, with a male: female ratio of 1:1.3 in rural areas and 1:1 in urban areas. Seventy-nine (52.7\%) children in urban areas were the first born compared with 39 (26\%) children in rural areas. This difference was statistically significant $(\mathrm{p}<0.001)$.

\section{Nutritional status of mothers and children}

Using a BMI of $18.5 \mathrm{~kg} / \mathrm{m}^{2}$ as the cut off point, 16 (10.7\%) mothers from rural communities and $4(2.7 \%)$ mothers from urban communities were undernourished. This difference was significant even after adjusting for social class (OR 4.3, 95\% $\mathrm{CI}=1.4-13.4, \mathrm{p}=0.014)$. However, there was no significant difference in the pevalence of stunting between mothers from rural and urban communities $(7.3 \%$ vs. $10.7 \%, \mathrm{p}=0.313)$ respectively.

The prevalences of underweight and stunting were significantly higher among children from rural than urban areas $(19.4 \%$ vs. $9.3 \%$, OR $3.8,95 \% \mathrm{CI}=1.8-8.1, \mathrm{p}<0.001)$ and $(43.3 \%$ vs. $12.6 \%$, OR $7.4,95 \% \mathrm{CI}=3.8-14.1, \mathrm{p}<0.001)$ respectively.

\section{Relationship between maternal and child nutritional status}

Table 2 shows the relationship between stunted mothers and the nutritional status of children. In rural communities, the risk of stunted mothers having chidren with 
Table 1 Socio-demographic characteristics and nutritional status of study population according to place of residence

\begin{tabular}{lccc}
\hline Parameters & Total $(\mathbf{n}=\mathbf{3 0 0})$ & Rural $(\mathbf{n}=\mathbf{1 5 0})$ & Urban $(\mathbf{n}=\mathbf{1 5 0})$ \\
\hline Mothers characteristics & & & P value \\
\hline Age (years)* & $30.0 \pm 5.6$ & $29.6 \pm 6.1$ & $30.4 \pm 5.6$ \\
Family setting & & & 0.186 \\
\hline \multicolumn{1}{c}{ Monogamy } & $265(88.3)$ & $119(79.3)$ & $146(97.3)$ \\
$\quad$ Polygamy & $35(11.7)$ & $3120.7)$ & $4(2.7)$ \\
Parity & & & $59(39.3)$ \\
\hline 1 & $83(27.7)$ & $24(16.0)$ & $82(54.7)$
\end{tabular}

Age at first birth

$\begin{array}{lccc}\text { ge at first birth } & 29(9.7) & 22(14.7) & 7(4.7) \\ 15-19 & 127(42.3) & 77(51.3) & 50(33.6) \\ 20-24 & 96(32.0) & 41(27.3) & 55(36.9) \\ 25-29 & 37(12.3) & 5(3.3) & 32(21.3) \\ 30-34 & 8(2.7) & 3(2.0) & 5(3.4) \\ 35-39 & \end{array}$

Educational level of mother

$\begin{array}{lccc}\text { No formal education } & 4(1.3) & 3(2.0) & 1(0.7) \\ \text { Primary } & 72(24.0) & 55(36.7) & 17(11.3) \\ \text { Secondary } & 155(51.7) & 79(52.7) & 76(50.7) \\ \text { Postsecondary } & 69(23.0) & 13(8.7) & 56(37.3)\end{array}$

Social class ${ }^{\#}$

\begin{tabular}{|c|c|c|c|c|}
\hline Upper & $19(6.3)$ & $0(0.0)$ & $19(12.7)$ & \\
\hline Middle & $50(16.7)$ & $15(10.0)$ & $35(23.3)$ & \\
\hline Lower & $231(77.0)$ & $135(90.0)$ & $96(64.0)$ & \\
\hline leight, less than $152 \mathrm{~cm}$ & $27(9.0)$ & $11(7.3)$ & $16(10.7)$ & 0.313 \\
\hline $\mathrm{MI}\left(\mathrm{kg} / \mathrm{m}^{2}\right)^{*}$ & $24.9 \pm 5.0$ & $24.4 \pm 5.0$ & $29.4 \pm 4.9$ & 0.092 \\
\hline Indernutrition, $\mathrm{BMI}<18.5 \mathrm{~kg} / \mathrm{m}^{2}$ & $20(6.7)$ & $16(10.7)$ & $4(2.7)$ & $0.014^{\dagger}$ \\
\hline \multicolumn{5}{|l|}{ hildren characteristics } \\
\hline ge (months)* & $25.3 \pm 16.4$ & $31.3 \pm 16.4$ & $19.3 \pm 4.0$ & 0.001 \\
\hline ex & & & & 0.248 \\
\hline
\end{tabular}

$\begin{array}{llll}\text { Male } & 142(47.3) & 66(44.0) & 76(50.7) \\ \text { Female } & 158(52.7) & 84(56.0) & 74(49.3)\end{array}$

Birth order

\begin{tabular}{|c|c|c|c|c|}
\hline 1 & $118(39.3)$ & $39(26.0)$ & $79(52.7)$ & \\
\hline $2-4$ & $161(53.6)$ & $97(64.7)$ & $64(42.7)$ & \\
\hline $5-7$ & $21(7.0)$ & $14(9.3)$ & $7(4.7)$ & \\
\hline Weight-for-age $z$ score, $<-2$ SD & $43(14.3)$ & $29(19.4)$ & $14(9.3)$ & 0.001 \\
\hline Height-for-Age z score, <-2 SD & $84(28.0)$ & $65(43.3)$ & $19(12.6)$ & 0.001 \\
\hline Weight-for-height z score, <-2 SD & $31(8.3)$ & $18(12.0)$ & $13(8.7)$ & 0.118 \\
\hline
\end{tabular}

Values are number (\%) unless otherwise stated; *values are mean $\pm \mathrm{SD} ;{ }^{\dagger}$ Adjusted for social class. ${ }^{\#}$ Upper social class includes parents such as senior government employee, high scale traders, and professionals, middle class include junior government employee, teachers and technicians while lower social class are peasant farmers, artisans, security agents, messengers, apprentice, laborers and the unemployed. 
Table 2 Relationship between mother's height and child's nutritional status ${ }^{\dagger}$

\begin{tabular}{|c|c|c|c|c|}
\hline \multicolumn{5}{|c|}{ Rural } \\
\hline Indicator of child & \multicolumn{2}{|c|}{ Mother's height (cm) } & \multirow[t]{2}{*}{ Odds ratio } & \multirow[t]{2}{*}{$95 \% \mathrm{Cl}$} \\
\hline Nutritional status & $<152$ & $\geq 152$ & & \\
\hline \multicolumn{5}{|c|}{ Weight-for-age Z-score } \\
\hline Underweight & $3(10.7)$ & $26(89.3)$ & 1.63 & \multirow[t]{2}{*}{$0.40-6.5$} \\
\hline Not underweight & $8(6.6)$ & $113(93.4)$ & 1 & \\
\hline \multicolumn{5}{|c|}{ Height-for-age Z-score } \\
\hline Stunted & $9(13.9)$ & $56(86.1)$ & $6.67^{*}$ & \multirow[t]{2}{*}{$1.39-32}$. \\
\hline Not stunted & $2(2.4)$ & $83(97.6)$ & 1 & \\
\hline \multicolumn{5}{|c|}{ Weight-for-height Z-score } \\
\hline Wasted & $2(11.1)$ & $16(88.9)$ & 1.71 & \multirow[t]{2}{*}{$0.34-8.62$} \\
\hline Not wasted & $9(6.8)$ & $123(93.2)$ & 1 & \\
\hline \multicolumn{5}{|c|}{ Urban } \\
\hline \multicolumn{5}{|c|}{ Weight-for-age Z-score } \\
\hline Underweight & $2(14.3)$ & $12(85.7)$ & 1.45 & \multirow[t]{2}{*}{$0.29-7.16$} \\
\hline Not underweight & $14(10.3)$ & $122(89.7)$ & 1 & \\
\hline \multicolumn{5}{|c|}{ Height-for-age Z-score } \\
\hline Stunted & $3(15.8)$ & $16(84.2)$ & 1.70 & \multirow[t]{2}{*}{$0.44-6.63$} \\
\hline Not stunted & $13(9.9)$ & $118(90.1)$ & 1 & \\
\hline \multicolumn{5}{|c|}{ Weight-for-height Z-score } \\
\hline Wasted & $0(0.0)$ & $13(100)$ & undefined & \\
\hline Not wasted & $16(11.7)$ & $121(88.3)$ & & \\
\hline
\end{tabular}

${ }^{*} p<0.01 ;{ }^{\dagger}$ Adjusted for social class, age at first birth, parity and family setting.

stunting is about 7 times higher than mothers that are not stunted (OR 6.7, 95\% CI = 1.4-32, $\mathrm{p}=0.007$ ).

Table 3 shows the relationship between under-nutrition in mothers and the nutritional status of children. In urban communities, the risk of undernourished mothers having childen with underweight and wasting were about 11 and 12 times respectively higher than mothers that were not undernourished (OR 11.2, 95\% CI $=1.4-86.5, \mathrm{p}=0.005$ ) and $(\mathrm{OR} 12.3,95 \% \mathrm{CI}=1.6-95.7, \mathrm{p}=0.003)$ respectively. Although, the risk of undernourished urban mothers having stunted children was about 2 times higher than those not undernourished, this difference was not significant (OR 2.4, 95\% CI = 0.2-24, $\mathrm{p}=0.452$ ).

\section{Risk factors for under-nutrition among mothers}

Tables 4 and 5 shows the influence of various sociodemographic factors on the nutritional status of mothers in rural and urban communities. In rural communities, there was significant association between nutritional status of mothers and family setting $\left(\chi^{2}=4.67, \mathrm{p}=0.031\right)$, age at first birth $\left(\chi^{2}=12.2, \mathrm{p}=0.016\right)$, and level of education of mothers $\left(x^{2}=34.7, \mathrm{p}<0.001\right)$. While in urban communities, nutritional status of mothers was significantly related to parity $\left(\chi^{2}=28.2, \mathrm{p}<0.001\right)$ and level of education of mothers $\left(\chi^{2}=15.4, \mathrm{p}<0.001\right)$.

\section{Risk factors for under-nutrition among children}

Tables 6 and 7 shows the influence of various sociodemographic factors on the nutritional status of children in rural and urban communities. In rural communities, Stunting was significantly related to lower parents' social class $(\chi 2=10.5, \mathrm{p}=0.005)$ only while wasting was significantly associated with low age of child $\left(\chi^{2}=15.0\right.$, $\mathrm{p}=0.005)$ and low educational level of the father $\left(\chi^{2}=\right.$ $22.8, \mathrm{p}=0.03)$. In urban communities, underweight was significantly related to gender $\left(\chi^{2}=4.81, \mathrm{p}=0.028\right)$ and birth order $\left(\chi^{2}=16.5, \mathrm{p}=0.006\right)$. Stunting was significantly related to gender $\left(\chi^{2}=7.0, \mathrm{p}=0.008\right)$ only while wasting was significantly related to birth order $\left(\chi^{2}=17.5\right.$, $\mathrm{p}=0.004)$ only.

\section{Discussion}

This study has shown that the prevalence of maternal and child under-nutrition among mothers and children in Lagos state, Nigeria remains high particularly in the rural communities. This is consistent with pevious studies on Nigerian women and children [13,14]. In our study, many of the socio-demographic factors which favour the occurrence of maternal and child under-nutrition were significantly higher in the rural communities. For instance, teenage pregnancy and high parity which are known to deplete mothers of nutrients because of physiological 
Table 3 Relationship between mother and child nutritional status ${ }^{\dagger}$

\begin{tabular}{|c|c|c|c|c|}
\hline \multicolumn{5}{|c|}{ Rural } \\
\hline Indicator of child & \multicolumn{2}{|c|}{ Mother's BMI $\left(\mathrm{kg} / \mathrm{m}^{2}\right)$} & \multirow[t]{2}{*}{ Odds ratio } & \multirow[t]{2}{*}{$95 \% \mathrm{Cl}$} \\
\hline Nutritional status & $<18.5$ & $\geq 18.5$ & & \\
\hline \multicolumn{5}{|c|}{ Weight-for-age Z-score } \\
\hline Underweight & $1(3.4)$ & $28(96.6)$ & 0.25 & $0.03-1.99$ \\
\hline Not underweight & $15(12.4)$ & $106(87.6)$ & 1 & \\
\hline \multicolumn{5}{|c|}{ Height-for-age Z-score } \\
\hline Stunted & $8(12.3)$ & $57(87.7)$ & 1.35 & $0.48-3.81$ \\
\hline Not stunted & $8(9.6)$ & $77(90.4)$ & 1 & \\
\hline \multicolumn{5}{|c|}{ Weight-for-height Z-score } \\
\hline Wasted & $3(16.7)$ & $15(83.3)$ & 1.83 & $0.47-7.17$ \\
\hline Not wasted & $13(10.0)$ & $119(90.0)$ & 1 & \\
\hline \multicolumn{5}{|c|}{ Urban } \\
\hline \multicolumn{5}{|c|}{ Weight-for-age Z-score } \\
\hline Underweight & $2(14.3)$ & $12(85.7)$ & $11.2^{*}$ & $1.44-86.5$ \\
\hline Not underweight & $2(1.5)$ & $134(98.5)$ & 1 & \\
\hline \multicolumn{5}{|l|}{ Height-for-age Z-score } \\
\hline Stunted & $1(5.3)$ & $18(94.7)$ & 2.37 & $0.23-24.03$ \\
\hline Not stunted & $3(2.3)$ & $128(97.7)$ & 1 & \\
\hline \multicolumn{5}{|c|}{ Weight-for-height Z-score } \\
\hline Wasted & $2(15.4)$ & $11(84.6)$ & $12.3^{*}$ & $1.57-95.7$ \\
\hline Not wasted & $2(1.5)$ & $135(98.5)$ & 1 & \\
\hline
\end{tabular}

${ }^{*} \mathrm{P}<0.01 ;{ }^{\dagger} \mathrm{Adjusted}$ for social class, age at first birth, parity and family setting.

immaturity and the stresses of multiple pregnancies and lactations with inadequate recuperative intervals between pregnancies were commoner in rural communities [15]. Similarly, low maternal education and low socio-economic class which limit mothers' utilisation of available resouces for the improvement of their own nutritional status and that of their families were also commoner in rural communities. These may explain the high prevalence of maternal and child under-nutrition in our rural communities.

The overall prevalence of under-nutrition for mothers in this study was $6.7 \%$; this is within the range of 5 to $20 \%$ reported for African women [16]. However, it is lower than the $25 \%$ reported for Ethiopian women [17], over $60 \%$ for Indian women [18] and $43.7 \%$ for women in Bangladesh [19]. This difference might be a reflection of the different environmental, cultural and socioeconomic situations in these countries which further implicates the important role of poverty, ignorance, food insecurity and infectious disease burden in maternal and child under-nutrition.

Despite several approaches and attempts at reducing rates of under-nutrition among Nigerian children, the prevalence remains high. In response to this problem of malnutrition, the Nigerian government launched its national policy on food and nutrition in 2002, with the goal of improving the nutritional status of all Nigerians [20]. This policy sets specific targets, which include reducing moderate and severe malnutrition among children under five years old by $30 \%$ by the year 2010 . Instead of a reduction, what has been observed is that the national prevalence of under-nutrition remained largely stable between the years 2003 and 2009, with the prevalences of underweight, wasting and stunting essentially static at $24 \%, 11 \%$ and $43 \%$, respectively [21]. In our study, the values from rural areas were similar to these national figures, while the values from urban areas were lower than the national figures, except for the prevalence of wasting. This implies that efforts at achieving effective control of under-nutrition should be concentrated in rural areas.

In both rural and urban communities, we observed a relationship between mother and child under-nutrition. This is similar to what was observed in rural Guinea by Mock et al [22] and in rural Ethiopia by Lindtjorn and Alemu [23]. In particular, in the rural communities, there was an association between chronic malnutrition in mothers and their children. This could be due to the influence of genetics on height, or could actually be due to a vicious circle of poorly nourished female children who grow up to be stunted and then bear their own children who are equally under-nourished, continuing the 
Table 4 Nutritional status in relation to socio-demographic variables for rural mothers

\begin{tabular}{cccc}
\hline Parameters & $\begin{array}{c}\text { Number of women } \\
(\mathbf{n}=\mathbf{1 5 0})\end{array}$ & $\begin{array}{c}\text { Number (\%) } \\
\text { malnourished }\end{array}$ & P values \\
\hline Age (years) & & & 0.090 \\
\hline $15-19$ & 1 & $0(0.0)$ & \\
$20-24$ & 25 & $2(8.0)$ & \\
$25-29$ & 56 & $11(19.6)$ & \\
$30-34$ & 36 & $2(5.6)$ & \\
$35-49$ & 32 & $1(3.1)$ &
\end{tabular}

\section{Marital status}

Not yet married

Married

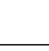

Widow

Family setting

Monogamy

Polygamy

Age at first birth

$$
\begin{aligned}
& 15-19 \\
& 20-24 \\
& 25-29 \\
& 30-34 \\
& 35-39
\end{aligned}
$$

\begin{tabular}{l} 
Parity \\
\hline 1 \\
2 \\
3 \\
4 \\
$5-7$
\end{tabular}

Education of mothers

\begin{tabular}{lccc}
\hline $\begin{array}{l}\text { No formal } \\
\text { education }\end{array}$ & 3 & $0(0.0)$ & \\
Primary & 55 & $1(1.8)$ & \\
Secondary & 79 & $15(19.0)$ & \\
Post-secondary & 13 & $0(0.0)$ & \\
Social class & & & 0.514 \\
\hline Upper & 0 & $0(0.0)$ & \\
Middle & 15 & $1(6.7)$ & \\
Lower & 135 & $15(11.1)$ & \\
\hline
\end{tabular}

cycle. It is worth noting that differences exist in the maternal-child nutrition associations across rural and urban communities. In rural communities, the maternal child nutrition association was chronic malnutrition while in urban it was acute malnutrition and this raises suspicion of persistent suboptimal nutritional practices in rural communities. Malnutrition has short and long term consequences on health of children. An important long term consequence of chronic malnutrition is that children with
Table 5 Nutritional status in relation to socio-demographic variables for urban mothers

\begin{tabular}{cccc}
\hline Parameters & $\begin{array}{c}\text { Number of women } \\
(\mathbf{n}=\mathbf{1 5 0 )}\end{array}$ & $\begin{array}{c}\text { Number (\%) } \\
\text { malnourished }\end{array}$ & P values \\
\hline Age (years) & & & 0.533 \\
\hline $15-19$ & 0 & $0(0.0)$ & \\
$20-24$ & 18 & $1(5.6)$ & \\
$25-29$ & 52 & $1(1.9)$ & \\
$30-34$ & 35 & $0(0.0)$ & \\
$35-49$ & 45 & $2(4.4)$ &
\end{tabular}

\begin{tabular}{lccc} 
Marital status & & & 0.478 \\
\hline Not yet married & 3 & $0(0.0)$ & \\
Married & 147 & $4(2.7)$ & \\
Family setting & & & 0.737 \\
\hline Monogamy & 146 & $4(2.7)$ & \\
Polygamy & 4 & $0(0.0)$ &
\end{tabular}

Age at first birth $\quad 0.130$

\begin{tabular}{lcc}
\hline $15-19$ & 7 & $1(14.3)$ \\
$20-24$ & 50 & $2(4.0)$ \\
$25-29$ & 55 & $1(1.8)$ \\
$30-34$ & 32 & $0(0.0)$ \\
$35-39$ & 5 & $0(0.0)$
\end{tabular}

\begin{tabular}{ccc} 
Parity & & \\
\hline 1 & 59 & $1(1.7)$ \\
2 & 49 & $1(2.0)$ \\
3 & 23 & 0000 \\
4 & 10 & $0(0.0)$ \\
$5-6$ & 9 & $2(22.2)$
\end{tabular}

\begin{tabular}{lccc} 
Education of mothers & & & 0.000 \\
\hline No formal education & 1 & $0(0.0)$ & \\
Primary & 17 & $3(17.6)$ & \\
Secondary & 76 & $1(1.3)$ & \\
Post-secondary & 56 & $0(0.0)$ & \\
Social class & & & 0.128 \\
\hline Upper & 19 & $0(0.0)$ & \\
Middle & 35 & $0(0.0)$ & \\
Lower & 96 & $4(4.4)$ & \\
\hline
\end{tabular}

stunting are prone to accumulation of body fat, especially central fat [24]. This could increase the burden of noncommunicable diseases such as diabetes mellitus and hypertension thereby further stretching the health system.

In this study, the identified risk factors for maternal under-nutrition were different across rural and urban communities. The only risk factor that cut across both communities was low maternal education. In the rural communities, the lower prevalence of maternal undernutrition in polygamous homes was suggestive of supportive role of co-wives for each other and possibly their 
Table 6 Nutritional status in relation to socio-demographic variables for rural children

\begin{tabular}{|c|c|c|c|c|c|c|c|}
\hline \multirow[t]{2}{*}{ Parameters } & \multirow{2}{*}{$\begin{array}{l}\text { Number of children } \\
\quad(\text { No }=150)\end{array}$} & \multicolumn{2}{|c|}{$\leq-2$ SD WAZ } & \multicolumn{2}{|c|}{$\leq-2$ SD HAZ } & \multicolumn{2}{|c|}{$\leq-2 \mathrm{SD} W H Z$} \\
\hline & & No (\%) & $P$ value & No (\%) & $P$ value & No (\%) & $P$ value \\
\hline Age (months) & & & 0.085 & & 0.693 & & 0.012 \\
\hline $0-11$ & 11 & $4(36.4)$ & & $4(36.4)$ & & $4(36.4)$ & \\
\hline $12-23$ & 42 & $13(31.0)$ & & $22(52.4)$ & & 7 (16.7) & \\
\hline 24- 35 & 34 & $2(5.9)$ & & $17(50.0)$ & & $0(0.0)$ & \\
\hline $36-47$ & 28 & $4(14.3)$ & & $7(25.0)$ & & 1 (3.6) & \\
\hline $48-59$ & 35 & $5(14.3)$ & & $13(37.1)$ & & $4(11.4)$ & \\
\hline Sex & & & 0.187 & & 0.026 & & 0.238 \\
\hline Male & 66 & $16(24.2)$ & & $27(40.9)$ & & $8(12.1)$ & \\
\hline Female & 84 & $12(14.2)$ & & $36(42.9)$ & & $8(9.5)$ & \\
\hline Birth order & & & 0.365 & & 0.241 & & 0.767 \\
\hline 1 & 38 & $10(26.3)$ & & $14(36.8)$ & & 7 (18.4) & \\
\hline 2 & 45 & $5(11.1)$ & & $23(51.1)$ & & $3(6.7)$ & \\
\hline 3 & 33 & $6(18.1)$ & & $13(39.4)$ & & $3(9.1)$ & \\
\hline 4 & 19 & $6(31.5)$ & & $10(52.6)$ & & $1(5.3)$ & \\
\hline $5-7$ & 14 & $1(7.1)$ & & $3(21.4)$ & & $2(14.2)$ & \\
\hline Total number of children & & & 0.070 & & 0.078 & & 0.947 \\
\hline 1 & 23 & $9(39.1)$ & & $10(43.5)$ & & $4(17.4)$ & \\
\hline 2 & 50 & $6(12.0)$ & & $21(42.0)$ & & $6(12.0)$ & \\
\hline 3 & 28 & $3(10.7)$ & & $16(57.1)$ & & $2(7.1)$ & \\
\hline 4 & 25 & $4(16.0)$ & & $6(24.0)$ & & $2(8.0)$ & \\
\hline$\geq 5$ & 23 & $6(26.1)$ & & $10(43.5)$ & & $2(8.7)$ & \\
\hline Educational level of mother & & & 0.706 & & 0.066 & & 0.741 \\
\hline No formal education & 3 & $2(66.7)$ & & $2(66.7)$ & & $1(33.3)$ & \\
\hline Primary & 55 & $11(20.0)$ & & $26(47.3)$ & & $7(12.7)$ & \\
\hline Secondary & 79 & $14(17.7)$ & & $32(40.5)$ & & $7(8.9)$ & \\
\hline Postsecondary & 13 & $2(15.4)$ & & $3(23.1)$ & & $1(7.7)$ & \\
\hline Educational level of father & & & 0.378 & & 0.142 & & 0.000 \\
\hline No formal education & 4 & $2(50.0)$ & & $3(75.0)$ & & $2(50.0)$ & \\
\hline Primary & 13 & $3(23.1)$ & & $5(38.5)$ & & $2(15.4)$ & \\
\hline Secondary & 99 & 18 (18.2) & & $49(49.5)$ & & $9(9.1)$ & \\
\hline Postsecondary & 34 & $7(14.6)$ & & $6(17.6)$ & & $5(8.8)$ & \\
\hline Social class & & & 0.330 & & 0.005 & & 0.352 \\
\hline Upper & 0 & $0(0.0)$ & & $0(0.0)$ & & $0(0.0)$ & \\
\hline Middle & 15 & $3(30.0)$ & & $1(6.7)$ & & $2(13.3)$ & \\
\hline Lower & 135 & 25 (18.5) & & $62(45.9)$ & & $14(10.4)$ & \\
\hline
\end{tabular}

husband. According to Madhaven [25], it is also possible for the co-wives to live in competition with each other resulting in poor maternal and child health. Similar to finding in other studies [16,17], mothers in our rural communities who started having children at a low age and those who started late were at risk of poor nutritional status. This has been ascribed to physiological unpreparedness and maternal depletion of nutrients. In our urban communities, mothers having more than 4 children were at risk of under-nutrition and this is also similar to the findings in other studies $[17,26]$. This is instructive, if one considers the fact that the standard of living in Lagos city is high and having more children ordinarily translate to more stresses of pregnancy, more financial burden, little food to eat and therefore poor maternal nutritional status. For children, the risk factors for underweight, wasting and stunting also differs across rural and urban communities. In rural communities, 
Table 7 Nutritional status in relation to socio-demographic variables for urban children

\begin{tabular}{|c|c|c|c|c|c|c|c|}
\hline Parameters & $\begin{array}{c}\text { Number of children } \\
(\mathrm{No}=150)\end{array}$ & $\begin{array}{c}\leq-2 \text { SD WAZ No (\%) } \\
\text { P value }\end{array}$ & & $\begin{array}{c}\leq-2 \text { SD HAZ No }(\%) \\
\text { P value }\end{array}$ & & $\begin{array}{c}\leq-2 \text { SD WHZ No (\%) } \\
\text { P value }\end{array}$ & \\
\hline Age (months) & & & 0.105 & & 0.713 & & 0.815 \\
\hline $0-11$ & 50 & $8(16.0)$ & & $8(16.0)$ & & $5(10.0)$ & \\
\hline $12-23$ & 48 & $6(12.5)$ & & $8(16.7)$ & & $6(12.5)$ & \\
\hline 24- 35 & 27 & $0(0.0)$ & & $2(7.4)$ & & $2(7.4)$ & \\
\hline $36-47$ & 18 & $0(0.0)$ & & $1(5.6)$ & & $0(0.0)$ & \\
\hline $48-59$ & 7 & $0(0.0)$ & & $0(0.0)$ & & $0(0.0)$ & \\
\hline Sex & & & 0.028 & & 0.008 & & 0.810 \\
\hline Male & 76 & $11(14.5)$ & & $15(19.7)$ & & $7(9.2)$ & \\
\hline Female & 74 & $3(4.1)$ & & $4(5.4)$ & & $6(8.1)$ & \\
\hline Birth order & & & 0.006 & & 0.653 & & 0.004 \\
\hline 1 & 79 & $6(7.6)$ & & $12(15.2)$ & & $7(8.9)$ & \\
\hline 2 & 34 & $4(11.8)$ & & $7(20.6)$ & & $2(5.9)$ & \\
\hline v3 & 21 & $0(0.0)$ & & $0(0.0)$ & & $0(0.0)$ & \\
\hline 4 & 9 & $2(22.2)$ & & $0(0.0)$ & & $2(22.2)$ & \\
\hline$\geq 5$ & 7 & $2(28.6)$ & & $0(0.0)$ & & $2(28.6)$ & \\
\hline Total number of children & & & 0.109 & & 0.109 & & 0.094 \\
\hline 1 & 59 & $8(13.6)$ & & $11(18.6)$ & & $5(8.5)$ & \\
\hline 2 & 48 & $2(4.2)$ & & $8(16.7)$ & & $4(8.3)$ & \\
\hline 3 & 22 & $0(0.0)$ & & $0(0.0)$ & & $0(0.0)$ & \\
\hline 4 & 12 & $2(16.7)$ & & $0(0.0)$ & & $2(16.6)$ & \\
\hline$\geq 5$ & 9 & $2(22.2)$ & & $0(0.0)$ & & $2(22.2)$ & \\
\hline Educational level of mother & & & 0.782 & & 0.402 & & 0.832 \\
\hline No formal education & 1 & $0(0.0)$ & & $0(0.0)$ & & $0(0.0)$ & \\
\hline Primary & 17 & $2(11.8)$ & & $1(5.9)$ & & $2(11.8)$ & \\
\hline Secondary & 76 & $10(13.2)$ & & $11(14.5)$ & & $6(7.9)$ & \\
\hline Postsecondary & 56 & $2(3.6)$ & & $7(12.5)$ & & $5(8.9)$ & \\
\hline Educational level of father & & & 0.910 & & 0.541 & & 0.953 \\
\hline No formal education & 1 & $0(0.0)$ & & $1(100.0)$ & & $0(0.0)$ & \\
\hline Primary & 7 & $2(28.6)$ & & $1(14.3)$ & & $2(28.6)$ & \\
\hline Secondary & 69 & $6(8.7)$ & & $8(11.6)$ & & $5(7.2)$ & \\
\hline Postsecondary & 73 & $6(8.2)$ & & $9(12.3)$ & & $6(8.2)$ & \\
\hline Social class & & & 0.197 & & 0.519 & & 0.472 \\
\hline Upper & 19 & $1(5.2)$ & & $1(5.2)$ & & $0(0.0)$ & \\
\hline Middle & 35 & $1(18.5)$ & & $4(11.4)$ & & $5(14.3)$ & \\
\hline Lower & 96 & $12(12.5)$ & & $14(14.6)$ & & $8(8.3)$ & \\
\hline
\end{tabular}

they were mostly socio-economic factors while in urban communities they were mostly biological factors. These risk factors need to be taking into consideration when planning interventional strategies aimed at reducing maternal and child under-nutrition in our rural and urban communities.

Though our study was limited to 2 local government areas of Lagos State, the findings can be generalized to the broader community. We recommend that further cross- sectional research work involving other communities and a larger sample frame is needed to better understand the relationship between mother and child under-nutrition and the risk factors for under-nutrition among mothers and children.

\section{Conclusions}

In conclusion, this study reveals high prevalence of maternal and child under-nutrition in both communities particularly 
in rural communities. It also confirms relationship between maternal and child under-nutrition. The risk factors for maternal and child under-nutrition differs across rural and urban communities. In order to reduce morbidity and mortality among mothers and children to the barest minimum, every effort must be made by the government to improve maternal and child nutritional status. This may involve public health enlightenment campaign discouraging teenage pregnancy and high parity of mothers which predisposes to poor nutritional status, complications during pregnancy and therefore risk of poor outcomes both for the mother and the child. There is also need to increase women education as this will make them receptive to health interventions that will improve their nutritional status and that of their child. It will also improve their earning power and hence good food puchasing power for the household.

\section{Competing interests}

The authors declare that they have no competing interest.

\section{Authors' contributions}

IOS concieved, designed, analyzed the data and wrote the first draft. 100 and WAO participated in the design, supervised data collection and guided writing of the manuscript. COS participated in the design and data collection. All authors read and approved the final manuscript.

\section{Acknowledgements}

We thank the executive councils of the Local Government Areas for giving us the permission to go into their communities. We also thank all the mothers and children who participated in this study.

\section{Author details \\ ${ }^{1}$ Department of Paediatrics and Child Health, Lagos State University College of Medicine, Ikeja, Lagos PMB 21266, Nigeria. ${ }^{2}$ Department of Nutrition and Dietetics, College of Food Sciences and Human Ecology, Federal University of Agriculture Abeokuta, FUNAAB P.O Box 54, Alabata Road, Abeokuta, Nigeria. ${ }^{3}$ Department of Obstetrics and Gynaecology, Lagos State University Teaching Hospital, No1-5, Oba Akinjobi Way, GRA, Ikeja, Lagos State, Nigeria. ${ }^{4}$ Department of Paediatrics and Child Health, Paediatrics Gastroenterology/ Hepatology/Nutrition Unit, Lagos State University Teaching Hospital, Ikeja, Lagos, Nigeria.}

Received: 6 September 2012 Accepted: 11 July 2013

Published: 23 July 2013

\section{References}

1. Prentice A: Nutritional requirements for growth, pregnancy and lactation: the Keneba experience. S Afr J Clin Nutr 1993, 6:33-38

2. Elshibly EM, Schmalisch G: The effect of maternal anthropometric characteristics and social factors on gestational age and birth weight in Sudanese newborn infants. BMC Publ Health 2008, 8:244

3. Administration Committee on Coordination-Sub-Committee on Nutrition: Second report on the world nutrition situation. New York: Global and regional results; 1992.

4. Muller O, Krawinkel M: Malnutrition and Health in Developing Countries. CMAJ 2005, 171:279-293.

5. Black RE, Allen LH, Bhutta ZA, Caulfield LE, de Onis M, Ezzati M, Mathers C, Rivera J, Maternal and Child under-nutrition Study Group: Maternal and child under-nutrition: global and regional exposures and health consequences. Lancet 2008, 371:243-260.

6. United Nations Children's Fund: Millennium Development Goals. Available at URL: http://www.un.org/millenniumgoals/.

7. Federal Government of Nigeria: Mid-point assessment of the Millennium Development Goals in Nigeria 2000-2007. Abuja. 2008.
8. National Bureau of Statistics: Poverty Profile of Nigeria. Abuja, Nigeria: National Bureau of Statistics; 2010

9. Ajayi A: Importance of nutrition in maternal, newborn and child health issues in Lagos State. http://www.docstoc.com/docs/26886405/Microsoft-PowerPointPresentation-on-the-Importance-of-Nutrition.

10. Maziya-Dixon B, Akinyele IO, Oguntona EB, Nokoe S, Sanusi RA, Harris E: Nigeria Food Consumption and Nurition Survey 2001-2003 Summary. Ibadan, Nigeria: International Institute of Tropical Agriculture; 2004.

11. Ogunlesi TA, Dedeke IOF, Kuponiyi OT: Socio-economic classification of children attending specialist paediatric centres in Ogun state, Nigeria. Niger Med Pract 2008, 54:21-25.

12. World Health Organization expert committee: Physical status, the use and interpretation of anthropometry. WHO Technical Report Ser 1995, 894:424-438.

13. Ene-Obong HN, Enugu Gl, Uwaegbute AC: Determinants of health and nutritional status of rural Nigerian women. J Health Popul Nutr 2001, 19:320-330.

14. Nigeria Demographic and Health Survey 2003. Calverton, Maryland: National Population Commission and ORC Macro; 2004

15. Lartey A: Maternal and child nutrition in Sub-Saharan Africa: challenges and interventions. Proc Nutr Soc 2008, 67:105-108

16. King JC: The risk of maternal nutritional depletion and poor outcomes increases in early or closely spaced pregnancies. J Nutr 2003, 133(5 Suppl 2):1732S-1736S.

17. Woldemariam G, Genebo T: Determinants of Nutritional Status of Women and Children in Ethiopia. Calverton, Maryland, USA: ORC Macro; 2000.

18. Bamji MS, Murthy PWS, Williams L, Rao MW: Maternal nutritional status and practices and perinatal, neonatal mortality in rural Andhra Pradesh, India. Indian J Med Res 2008, 127:44-51.

19. Rahman MM, Nasrin SO: Mother's nutritional status in an impoverished nation: Evidence from rural Bangladesh. Internet J Nutr Wellness 2009, 7:1

20. Akinyele 1O: Ensuring Food and Nutrition Security in Rural Nigeria: An Assessment of the Challenges, Information Needs, and Analytical Capacity. Abuja, Nigeria: Nigeria Strategy Support Program; 2009.

21. The State of the World Children: Children in an urban world. New York: UNICEF; 2012.

22. Mock NB, Magnani RJ, Abdoh AA, Kondé MK: Intra-household correlations in maternal-child nutritional status in rural Guinea: implications for programme-screening strategies. Bull World Health Organ 1994, 72:119-127.

23. Lindtjørn B, Alemu T: Intra-household correlations of nutritional status in rural Ethiopia. Int J Epidemiol 1997, 26:160-165.

24. Kalhan SC, Prentice AM, Yajnik CS: Emerging Societies - Coexistence of Childhood Malnutrition and Obesity. In , Nestlé Nutr Inst Workshop Ser Pediatr ProgramKarger AG, Basel: Nestec Ltd., Vevey/S; 2009:95-108.

25. Madhavan S, Townsend N: The social context of children's nutritional status in rural South Africa. Scand J Publ Health 2007, 69(Suppl):107-117.

26. Pei $L$, Ren $L$, Wang $D$, Yan $H$ : The evaluation of maternal health in rural western China. Ethn Health 2013. Mar 7. [Epub ahead of print] PubMed PMID: 23469986

\section{doi:10.1186/1756-0500-6-286}

Cite this article as: Senbanjo et al:: Maternal and child under-nutrition in rural and urban communities of Lagos state, Nigeria: the relationship and risk factors. BMC Research Notes 2013 6:286.

\section{Submit your next manuscript to BioMed Central and take full advantage of:}

- Convenient online submission

- Thorough peer review

- No space constraints or color figure charges

- Immediate publication on acceptance

- Inclusion in PubMed, CAS, Scopus and Google Scholar

- Research which is freely available for redistribution 